\title{
Threshold for Transitory Diarrhea Induced by Ingestion of Xylitol and Lactitol in Young Male and Female Adults
}

\author{
Tsuneyuki OKU and Sadako NAKAMURA \\ Graduate School of Human Health Science, Siebold University of Nagasaki, Nagayo, \\ Nagasaki 851-2195, Japan \\ (Received May 16, 2006)
}

\begin{abstract}
Summary The ingestion of a sufficiently large amount of non-digestible and/or nonabsorbable sugar substitutes causes overt diarrhea. The objective is to estimate the noneffective dosage that does not cause transitory diarrhea for xylitol, lactitol, and erythritol in healthy subjects. Twenty-seven males and 28 females gave informed and written consent to participate, were selected, and participated in the study. The oral dose levels of xylitol were $10,20,30,40$ and $50 \mathrm{~g}$, while those of lactitol were 10, 20, 30, and $40 \mathrm{~g}$. Those of erythritol were 20,30, 40 and $50 \mathrm{~g}$. The test substance was ingested in $150 \mathrm{~mL}$ of water $2-3 \mathrm{~h}$ after a meal. The ingestion order progressed from the smallest to larger amounts, and stopped at the dose that caused diarrhea, or at the largest dose level to be set up. The noneffective dose level of xylitol was $0.37 \mathrm{~g} / \mathrm{kg}$ B.W. for males and $0.42 \mathrm{~g} / \mathrm{kg} \mathrm{B} . W$. for females. That of lactitol was $0.25 \mathrm{~g} / \mathrm{kg} \mathrm{B} . W$. for males and $0.34 \mathrm{~g} / \mathrm{kg} \mathrm{B}$.W. for females, and that of erythritol was $0.46 \mathrm{~g} / \mathrm{kg} \mathrm{B.W}$. for males and $0.68 \mathrm{~g} / \mathrm{kg}$ B.W. for females. These results appear reasonable, because xylitol is poorly absorbed from the small intestine, and the absorption rate is less than that of erythritol, while lactitol is not hydrolyzed. Non-digestible and/or non-absorbable sugar alcohols and oligosaccharides with beneficial health effects inevitably cause overt diarrhea. The estimation of the non-effective dose level of these sugar substitutes is essential and important to produce processed foods that the consumer can use safely and with confidence.
\end{abstract}

Key Words non-effective dosage, xylitol, lactitol, erythritol, transitory diarrhea

Recently, bulking sucrose substitutes with beneficial health effects have been actively developed and are added to various processed foods which are marketed with emphasis on their special physiological function $(1,2)$ and they are also used as food additives.

Non-digestible and/or non-absorbable oligosaccharides and sugar alcohols escape digestion and absorption in the small intestine, and are fermented by microbes in the large intestine (3-5). However, the ingestion of a sufficiently large amount of non-digestible and/ or non-absorbable sugar substitutes causes overt diarrhea, and frequently minor symptoms such as abdominal distention and flatus, in humans and animals (610). The mechanism of diarrhea induction is considered to be similar to that associated with lactose intolerance. The diarrhea is due to the osmotic retention of fluid in the small and large intestines, and spontaneously resolves when the material is excreted $(11,12)$.

Xylitol is a pentose alcohol and is made by hydrogenating xylose which is produced by the hydrolysis of hemicellulose. The sweetness of xylitol is similar to that of sucrose. Xylitol is barely absorbed from the small intestine without digestion $(13,14)$. A fraction of ingested xylitol is absorbed from the small intestine and the greater part, which is not absorbed from the small intestine, is transferred to the large intestine.

Lactitol is a disaccharide alcohol and is made by

E-mail: okutsune@sun.ac.jp hydrogenating lactose. It is scarcely digested by intestinal enzymes, and most orally ingested lactitol reaches the large intestine (13-15). Xylitol and lactitol ingested in general are completely fermented by intestinal microbes in the large intestine, and are metabolized to short-chain fatty acids, carbon dioxide, hydrogen, and methane, contributing to the cellular composition of the intestinal microbes $(4,5,16-19)$. The high osmotic diarrhea is induced when an amount of xylitol or lactitol beyond the utilization capacity of the intestinal microbiota arrives at the large intestine.

It is thought that lactitol has a greater tendency to cause high osmotic diarrhea than xylitol, when the same amounts of each test substance are ingested by the same subjects. Erythritol is spontaneously absorbed from the small intestine and readily excreted into the urine without any decomposition $(20,21)$. As a result, only a small percentage of ingested erythritol reaches the lower intestine. Therefore, erythritol might be less apt to cause diarrhea, in comparison with xylitol. In addition, female subjects have generally higher resistance to the high osmotic diarrhea due to the oral ingestion of these sugar substitutes (9).

The non-effective dose level at which transitory diarrhea is not induced has been estimated for some nondigestible and/or non-absorbable oligosaccharides and sugar alcohols in female subjects. But, that for male subject is few. The purpose of this study is to estimate the non-effective dose levels at which xylitol and lactitol 
do not induce transitory diarrhea in healthy male and female subjects. Erythritol, for which the non-effective dose level has already been measured, is used in comparison with that of xylitol in this study $(9,20,21)$.

\section{EXPERIMENTAL SUBJECTS AND METHODS}

Subjects. The subjects who applied for public participation in this study were 39 males and 38 females, all of whom were university students. They had no history of gastrointestinal disease and had not been treated with antibiotics or laxatives in the 2 -wk period before the experiment. They were asked their daily frequency of defecation. None had severe constipation. Finally, 27 male and 28 female subjects gave informed and written consent to participate, were selected, and participated in the study (Table 1).

There were fewer subjects in the erythritol and lactitol intake experiments than in the xylitol ingestion experiment, because some subjects did not feel well or could not ingest the whole quantity of testing material during the experiment.

Materials. Xylitol (more than 99\% purity) and lactitol (more than 99\% purity) were kindly provided by Danisco Japan Ltd. (Tokyo) and erythritol (more than 99\% purity) was kindly given by Nikken Chemical Co., Ltd. (Tokyo). All of the chemicals used were of analytical grade or the highest grade available.

Protocol of administration of test substances. In order to estimate the non-effective dose level at which the test material does not induce transitory diarrhea, several levels of xylitol, lactitol, and erythritol were administered to each individual subject. The dose levels of xylitol, which is barely absorbed from the small intestine, were $10,20,30,40$, and $50 \mathrm{~g}$, while those of lactitol, which is non-digestible and easily induces diarrhea, were $10,20,30$, and $40 \mathrm{~g}$. The dose levels of erythritol, which is readily absorbed from the small intestine and quickly excreted into the urine without any degradation, were $20,30,40$, and $50 \mathrm{~g}$. The intake of more than $50 \mathrm{~g}$ of test materials is too much for subjects and causes them distress. The test substance was dissolved in $150 \mathrm{~mL}$ of distilled water and ingested $2-3 \mathrm{~h}$ after a meal, usually breakfast. The ingestion order of the test substance progressed from the smallest to larger amounts, and stopped at the dose that caused diarrhea, or at the largest dose level set up in the study. The ingestion of each test substance was carried out for at least $1 \mathrm{wk}$ interval to avoid any effect from the change of intestinal microflora and the abdominal symptoms caused by the loading of the previous test substance $(6$, 9, 10). The diarrhea and abdominal symptoms had

Table 1. Characteristics of the subjects.

\begin{tabular}{lrr}
\hline & \multicolumn{1}{c}{$\begin{array}{c}\text { Male } \\
(n=27)\end{array}$} & $\begin{array}{r}\text { Female } \\
(n=28)\end{array}$ \\
\hline Age $(\mathrm{y})$ & $19.9 \pm 1.2$ & $21.2 \pm 2.2$ \\
Weight $(\mathrm{kg})$ & $63.4 \pm 9.4$ & $49.9 \pm 5.9$ \\
Height $(\mathrm{cm})$ & $172.0 \pm 5.1$ & $156.8 \pm 3.3$ \\
\hline
\end{tabular}

appeared within a few hours after ingestion of test substances and disappeared within $24 \mathrm{~h}$. Xylitol was administered at first to all subjects, erythritol was second, and lactitol was third.

From the day prior to administration, all subjects were required to avoid the ingestion of foods and beverages containing non-digestible sugar substitutes and fermented foods which might cause diarrhea. On the day of administration, subjects were not permitted to eat or to drink any foods at least $3 \mathrm{~h}$ before and after ingestion of the test substance.

Observation of fecal shape and frequency, gastrointestinal symptoms and physical condition. After administration of the test substance, the type and onset time of abdominal symptoms, the frequency of defecation, and the macroscopic finding of stool shape were recorded by the subjects themselves. The examiner explained to all of the subjects the method of self-recording and the classification of stool shape and abdominal symptoms, and confirmed recordings in these questionnaires as they were received. The questionnaire on diarrhea included the examination of stool shape, and the following descriptors: stage 1, very hard (ball-shaped, like rabbit stool); stage 2, hard; stage 3, normal (banana-shaped); stage 4 , soft (pastelet); stage 5 , very soft (muddy); and stage 6 , watery $(9,10,22)$. The defecation of muddy or watery stool was defined as diarrhea in this study. The questionnaire on abdominal symptoms asked about the experience of upper and lower abdominal pain, vomiting, nausea, thirst, flatus, distention, and borborygmus $6 \mathrm{~h}$ after ingestion of the test substance. Food intake was also recorded by individual subjects before and on the day of administration of the test substances, and nutrient intake was calculated.

Statistical analysis and calculation of results. The significance of the linear regressions were tested using SPSS using a significant level of $p<0.05$.

Ethical considerations. This study was approved by the Ethical Committee of Siebold University of Nagasaki Prefecture and informed consent was obtained from all subjects. All studies were conducted in the Laboratory of Public Health Nutrition, Siebold University of Nagasaki.

\section{RESULTS}

\section{The condition of subjects}

The participants in the experiments were 27 male and 28 female subjects, who observed the relationship between the ingestion of test substances and incidence of diarrhea. The average frequency of defecation in their ordinary life was $6.5 \mathrm{~d}$ per week for male subjects and $4.8 \mathrm{~d}$ per week for female subjects. Two male subjects had 4 or fewer defecation days per week, and 5 male subjects had 5 or more defecation days per week. In terms of the female subjects, 16 subjects had 4 or fewer defecation days per week and 12 subjects had 5 or more defecation days per week. The daily average intake of energy and protein before and on the experimental day was $2,183 \pm 312 \mathrm{kcal}$ and $78 \pm 15 \mathrm{~g}$ for males, and $1,875 \pm 230 \mathrm{kcal}$ and $65 \pm 13 \mathrm{~g}$ for females, respectively. 
Table 2. Xylitol, erythritol, and lactitol intake and incidence of diarrhea in normal male subjects.

\begin{tabular}{|c|c|c|c|c|c|c|c|c|c|c|c|c|c|}
\hline \multirow{2}{*}{ Subject No. } & \multicolumn{5}{|c|}{ Xylitol intake (g) } & \multicolumn{4}{|c|}{ Erythritol intake (g) } & \multicolumn{4}{|c|}{ Lactitol intake (g) } \\
\hline & 10 & 20 & 30 & 40 & 50 & 20 & 30 & 40 & 50 & 10 & 20 & 30 & 40 \\
\hline 1 & $\times$ & $\bullet$ & & & & & - & - & - & - & - & - & - \\
\hline 2 & $\times$ & $x$ & $\bullet$ & & & $\times$ & $x$ & $\bullet$ & & $\times$ & $x$ & $\bullet$ & \\
\hline 3 & $x$ & $x$ & $\bullet$ & & & $x$ & $x$ & $\bullet$ & & $\times$ & $x$ & $\bullet$ & \\
\hline 4 & $x$ & $x$ & • & & & $x$ & $x$ & - & & - & - & - & - \\
\hline 5 & $x$ & $x$ & - & & & & - & - & - & - & - & - & - \\
\hline 6 & $x$ & $x$ & $x$ & $\bullet$ & & & $\times$ & $\bullet$ & & $\times$ & $\times$ & $\bullet$ & \\
\hline 7 & $x$ & $\times$ & $x$ & $\bullet$ & & & $x$ & $\bullet$ & & $\times$ & $\times$ & $\bullet$ & \\
\hline 8 & $x$ & $x$ & $x$ & $\bullet$ & & & $x$ & $\bullet$ & & $x$ & - & - & - \\
\hline 9 & $x$ & $x$ & $x$ & • & & & $x$ & $x$ & • & $x$ & - & & \\
\hline 10 & $x$ & $x$ & $x$ & • & & & $x$ & $x$ & • & - & - & - & - \\
\hline 11 & $x$ & $x$ & $x$ & • & & & $x$ & $x$ & - & - & - & - & - \\
\hline 12 & $x$ & $x$ & $x$ & - & & & $x$ & $\times$ & $x$ & $\times$ & • & & \\
\hline 13 & $x$ & $x$ & $x$ & - & & & $x$ & $x$ & $x$ & $x$ & $x$ & - & \\
\hline 14 & $x$ & $\times$ & $x$ & $\bullet$ & & & $x$ & $x$ & $x$ & $x$ & $x$ & 0 & \\
\hline 15 & $x$ & $x$ & $\times$ & $\bullet$ & & & $\times$ & $\times$ & $\times$ & $x$ & $x$ & $\bullet$ & \\
\hline 16 & $x$ & $\times$ & $x$ & • & & & - & $\times$ & - & $x$ & $x$ & - & \\
\hline 17 & $x$ & $x$ & $x$ & $x$ & $\bullet$ & & $\times$ & $\times$ & $\bullet$ & $x$ & $\times$ & $\bullet$ & \\
\hline 18 & $x$ & $x$ & $x$ & $x$ & $\bullet$ & & $x$ & $x$ & $\bullet$ & - & - & - & - \\
\hline 19 & $x$ & $\times$ & $x$ & $\times$ & $\bullet$ & & $x$ & $\times$ & $\times$ & $\times$ & $\times$ & $\bullet$ & \\
\hline 20 & $x$ & $\times$ & $x$ & $x$ & • & & $x$ & $\times$ & $x$ & $\times$ & $\times$ & $\times$ & $\bullet$ \\
\hline 21 & $x$ & $\times$ & $x$ & $\times$ & $\bullet$ & & $x$ & $\times$ & $x$ & $x$ & $\times$ & $\times$ & • \\
\hline 22 & $x$ & $\times$ & $x$ & $x$ & $\bullet$ & & $x$ & $\times$ & $x$ & $x$ & $x$ & $x$ & $\bullet$ \\
\hline 23 & $x$ & $x$ & $x$ & $x$ & $x$ & & $\times$ & $\times$ & $x$ & $\times$ & $x$ & $\bullet$ & \\
\hline 24 & $x$ & $\times$ & $x$ & $x$ & $\times$ & & $x$ & $\times$ & $x$ & $\times$ & $\times$ & $\bullet$ & \\
\hline 25 & $x$ & $x$ & $x$ & $x$ & $x$ & & $x$ & $x$ & $x$ & $x$ & $x$ & $x$ & 0 \\
\hline 26 & $x$ & $x$ & $x$ & $\times$ & $x$ & & $x$ & $\times$ & $x$ & $\times$ & $x$ & $x$ & $x$ \\
\hline 27 & $x$ & $x$ & $\times$ & $x$ & $x$ & & $\times$ & $\times$ & $x$ & $x$ & $x$ & $\times$ & $x$ \\
\hline Number & 27 & 27 & 26 & 22 & 11 & 2 & 24 & 24 & 18 & 20 & 20 & 18 & 6 \\
\hline Diarrhea & 0 & 1 & 4 & 11 & 6 & 0 & 0 & 6 & 5 & 0 & 2 & 12 & 4 \\
\hline$\%$ & 0 & 3.7 & 15.4 & 50.0 & 54.5 & 0.0 & 0.0 & 25.0 & 27.8 & 0.0 & 10.0 & 66.7 & 66.7 \\
\hline Cumulative \% & 0.0 & 3.7 & 18.5 & 59.3 & 81.5 & 0.0 & 0.0 & 25.0 & 45.8 & 0.0 & 10.0 & 70.0 & 90.0 \\
\hline
\end{tabular}

-, experienced diarrhea; $\times$, did not experience diarrhea.

Relationship between test substance intake and diarrhea incidence in male subjects

Table 2 shows the relationship between the intake of test substances and diarrhea incidence in male subjects. When $10 \mathrm{~g}$ of xylitol were ingested once by 27 male subjects, none had watery or muddy feces. Ingestion of $20 \mathrm{~g}$ of xylitol caused diarrhea in only one of 27 male subjects. After ingesting $30 \mathrm{~g}$ of xylitol, 4 of the remaining 26 subjects experienced diarrhea, and ingestion of $40 \mathrm{~g}$ of xylitol caused diarrhea in 11 of 22 subjects. The ingestion through $50 \mathrm{~g}$ of xylitol, which is the maximum dose level in this study, caused diarrhea in 22 of 27 subjects $(81.5 \%)$, while 5 of 27 subjects $(18.5 \%)$ did not have diarrhea even at the intake level of $50 \mathrm{~g}$ of xylitol.

Twenty-four of 27 subjects participated in the erythritol ingestion experiment (Table 2). The minimal ingestion of erythritol was $30 \mathrm{~g}$, because it has less of a tendency to cause diarrhea than xylitol. Three subjects, who were judged to be not resistant for diarrhea in the xylitol experiment, started from $20 \mathrm{~g}$ ingestion, but none had diarrhea. When $30 \mathrm{~g}$ of erythritol were ingested once by each of 24 male subjects, none had diarrhea. Ingestion of $40 \mathrm{~g}$ of erythritol caused diarrhea in 6 of 24 male subjects. Ingestion of $50 \mathrm{~g}$ of erythritol caused diarrhea in 5 of 18 subjects. The $50 \mathrm{~g}$ intake of erythritol, which was the highest dose used in the study, caused diarrhea in 11 of 24 subjects (45.8\%). Still, 13 of 24 subjects (54.2\%) did not have diarrhea even after ingesting $50 \mathrm{~g}$ of erythritol.

Twenty of 27 subjects participated in the lactitol ingestion experiment (Table 2). The minimum ingestion of lactitol was $10 \mathrm{~g}$, because it more readily induces diarrhea, in comparison with xylitol. Ingestion of $10 \mathrm{~g}$ of lactitol did not cause diarrhea in any of 20 male subjects. Ingestion of $20 \mathrm{~g}$ of lactitol caused diarrhea in 2 of 20 male subjects. After ingesting $30 \mathrm{~g}$ of lactitol, 12 of 18 remaining subjects experienced diarrhea. The ingestion of $40 \mathrm{~g}$ of lactitol, the highest dose level, caused diarrhea in 18 of 20 subjects $(90 \%)$. Still, 2 of 20 subjects $(10 \%)$ did not have diarrhea even after ingesting $40 \mathrm{~g}$ of lactitol.

Relationship between test substance intake and diarrhea incidence in female subjects

Twenty-eight female subjects participated in the xyli- 
Table 3. Xylitol, erythritol, and lactitol intake and incidence of diarrhea in normal female subjects.

\begin{tabular}{|c|c|c|c|c|c|c|c|c|c|c|c|c|c|}
\hline \multirow{2}{*}{ Subject No. } & \multicolumn{5}{|c|}{ Xylitol intake (g) } & \multicolumn{4}{|c|}{ Erythritol intake (g) } & \multicolumn{4}{|c|}{ Lactitol intake (g) } \\
\hline & 10 & 20 & 30 & 40 & 50 & 20 & 30 & 40 & 50 & 10 & 20 & 30 & 40 \\
\hline 1 & $\times$ & $\bullet$ & & & & $\times$ & $\times$ & $\times$ & $\bullet$ & $x$ & $\bullet$ & & \\
\hline 2 & $\times$ & • & & & & - & $\times$ & - & - & $\times$ & $\bullet$ & & \\
\hline 3 & $x$ & $x$ & $\bullet$ & & & & $x$ & $\times$ & $\bullet$ & $x$ & $x$ & - & \\
\hline 4 & $\times$ & $x$ & $\bullet$ & & & & $\times$ & $\times$ & $\bullet$ & $x$ & $\times$ & $\bullet$ & \\
\hline 5 & $\times$ & $\times$ & $\bullet$ & & & - & $x$ & - & - & $x$ & $\times$ & $\bullet$ & \\
\hline 6 & $\times$ & $\times$ & $\bullet$ & $\bullet$ & & & $\times$ & $\times$ & $\times$ & $x$ & $\bullet$ & & \\
\hline 7 & $x$ & $x$ & $x$ & - & & & $x$ & $\bullet$ & & $x$ & $x$ & $\bullet$ & \\
\hline 8 & $\times$ & $x$ & $x$ & $\bullet$ & & & $x$ & $\bullet$ & & $x$ & $\times$ & $\bullet$ & \\
\hline 9 & $\times$ & $x$ & $\times$ & 0 & & & $x$ & $\times$ & - & $x$ & $\times$ & • & \\
\hline 10 & $\times$ & $x$ & $\times$ & $\bullet$ & & & $\times$ & $\times$ & $x$ & $\times$ & $\times$ & $\bullet$ & \\
\hline 11 & $\times$ & $x$ & $\times$ & • & & & $x$ & $\times$ & $\times$ & $x$ & $\times$ & • & \\
\hline 12 & $\times$ & $x$ & $\times$ & $x$ & $\bullet$ & & $\times$ & $\times$ & $x$ & $x$ & $\times$ & $\bullet$ & \\
\hline 13 & $x$ & $x$ & $\times$ & $x$ & 0 & & $x$ & $\times$ & - & $x$ & 0 & & \\
\hline 14 & $x$ & $x$ & $x$ & $x$ & 0 & & $x$ & $x$ & 0 & $x$ & $x$ & • & \\
\hline 15 & $\times$ & $x$ & $\times$ & $x$ & • & & $\times$ & $\times$ & $x$ & $x$ & $x$ & $\times$ & - \\
\hline 16 & $x$ & $x$ & $x$ & $x$ & 0 & & $x$ & $x$ & $x$ & $x$ & $x$ & - & \\
\hline 17 & $\times$ & $\times$ & $\times$ & $\times$ & $\bullet$ & & $\times$ & $\times$ & $\times$ & $\times$ & $\times$ & $\bullet$ & \\
\hline 18 & $\times$ & $x$ & $x$ & $x$ & $x$ & & $\times$ & $\times$ & $\times$ & $x$ & $x$ & - & \\
\hline 19 & $\times$ & $\times$ & $\times$ & $\times$ & $\times$ & & $\times$ & $\times$ & $\times$ & $\times$ & $\times$ & $\times$ & $\times$ \\
\hline 20 & $x$ & $x$ & $x$ & $x$ & $x$ & & $\times$ & $\times$ & $x$ & $x$ & $x$ & $x$ & 0 \\
\hline 21 & $\times$ & $x$ & $\times$ & $\times$ & $\times$ & & $\times$ & $\times$ & $\times$ & $\times$ & $\times$ & • & \\
\hline 22 & $\times$ & $x$ & $\times$ & $x$ & $\times$ & & $x$ & $\times$ & $\times$ & $x$ & $\times$ & $\times$ & $x$ \\
\hline 23 & $\times$ & $\times$ & $\times$ & $\times$ & $\times$ & & $\times$ & $\times$ & $\times$ & $\times$ & $\times$ & $\times$ & $\times$ \\
\hline 24 & $\times$ & $x$ & $\times$ & $x$ & $\times$ & & $\times$ & $x$ & $\times$ & $x$ & $\times$ & $\times$ & 0 \\
\hline 25 & $\times$ & $x$ & $\times$ & $\times$ & $\times$ & & $\times$ & $\times$ & $\times$ & $\times$ & $\times$ & $\times$ & $\times$ \\
\hline 26 & $x$ & $x$ & $\times$ & $x$ & $\times$ & & $x$ & $\times$ & $x$ & $x$ & $\times$ & $\times$ & $x$ \\
\hline 27 & $\times$ & $x$ & $\times$ & $x$ & $\times$ & & $\times$ & $\times$ & $\times$ & $x$ & $\times$ & $\times$ & ○ \\
\hline 28 & $\times$ & $x$ & $\times$ & $x$ & $x$ & & $\times$ & $\times$ & $\times$ & $x$ & $\times$ & $\times$ & $x$ \\
\hline Number & 28 & 28 & 26 & 22 & 16 & 1 & 26 & 26 & 24 & 28 & 28 & 24 & 10 \\
\hline Diarrhea & 0 & 2 & 4 & 6 & 6 & 0 & 0 & 2 & 6 & 0 & 4 & 14 & 4 \\
\hline$\%$ & 0 & 7.1 & 15.4 & 27.3 & 37.5 & 0.0 & 0.0 & 7.7 & 25.0 & 0.0 & 14.3 & 58.3 & 40.0 \\
\hline Cumulative \% & 0.0 & 7.1 & 21.4 & 42.9 & 64.3 & 0.0 & 0.0 & 7.7 & 30.8 & 0.0 & 14.3 & 64.3 & 78.6 \\
\hline
\end{tabular}

- experienced diarrhea; $\times$, did not experience diarrhea.

tol ingestion experiment. Table 3 shows the relationship between the intake of test substances and diarrhea incidence in female subjects. When $10 \mathrm{~g}$ of xylitol were ingested once in 28 female subjects, none had diarrhea. Ingestion of $20 \mathrm{~g}$ of xylitol caused diarrhea in 2 of 28 female subjects. After ingesting $30 \mathrm{~g}$ of xylitol, 4 of 26 remaining subjects experienced diarrhea, and intake of $40 \mathrm{~g}$ of xylitol caused overt diarrhea in 6 of 22 subjects. The intake of $50 \mathrm{~g}$ of xylitol caused diarrhea in 18 of 28 subjects $(64.3 \%)$, while 10 of 28 subjects $(35.7 \%)$ did not have diarrhea even after ingesting $50 \mathrm{~g}$ of xylitol.

Twenty-six of 28 subjects participated in the erythritol intake experiment (Table 3). When $30 \mathrm{~g}$ of erythritol were ingested, none of 26 female subjects had diarrhea. Intake of $40 \mathrm{~g}$ of erythritol caused diarrhea in 2 of 26 female subjects. After ingesting $50 \mathrm{~g}$ of erythritol, 6 of 24 remaining subjects experienced diarrhea. The intake of $50 \mathrm{~g}$ of erythritol caused diarrhea in 8 of 26 subjects $(30.8 \%)$. Still, 18 of 26 subjects $(69.2 \%)$ did not have diarrhea even at the highest dose of $50 \mathrm{~g}$ of erythritol.

All 28 subjects participated in the lactitol ingestion experiment (Table 3). Of 28 female subjects who ingested $10 \mathrm{~g}$ of lactitol, none had diarrhea. Intake of $20 \mathrm{~g}$ of lactitol caused diarrhea in 4 of 28 female subjects. The intake of $30 \mathrm{~g}$ of lactitol caused diarrhea in 14 of 24 remaining subjects. The $40 \mathrm{~g}$ intake of lactitol, the highest dose used in the study, caused diarrhea in 22 of 28 subjects $(78.6 \%)$. Still, 6 of 28 subjects $(21.4 \%)$ did not have diarrhea even after ingesting $40 \mathrm{~g}$ of lactitol.

Non-effective dose levels of xylitol, lactitol and erythritol for transitory diarrhea in male subjects

The relationship between the minimal dose levels of xylitol ( $\mathrm{g}$ per kg of body weight) and cumulative diarrhea incidence (\%) in all subjects is shown in Fig. 1. The cumulative incidence (\%) of diarrhea is shown as the ratio of subjects with diarrhea to the total subjects $(n=27)$ participating in the present study of xylitol. The point of lowest incidence $(1 / 27=3.7 \%)$ shows the subject who had diarrhea at the lowest intake of test substance per $\mathrm{kg}$ of body weight. The second lower point $(2 / 27=7.4 \%)$ shows that the subject had diarrhea at the second lowest intake of the test substance. Each subsequent point shows the incidence in the 3rd to $22 \mathrm{nd}$ 

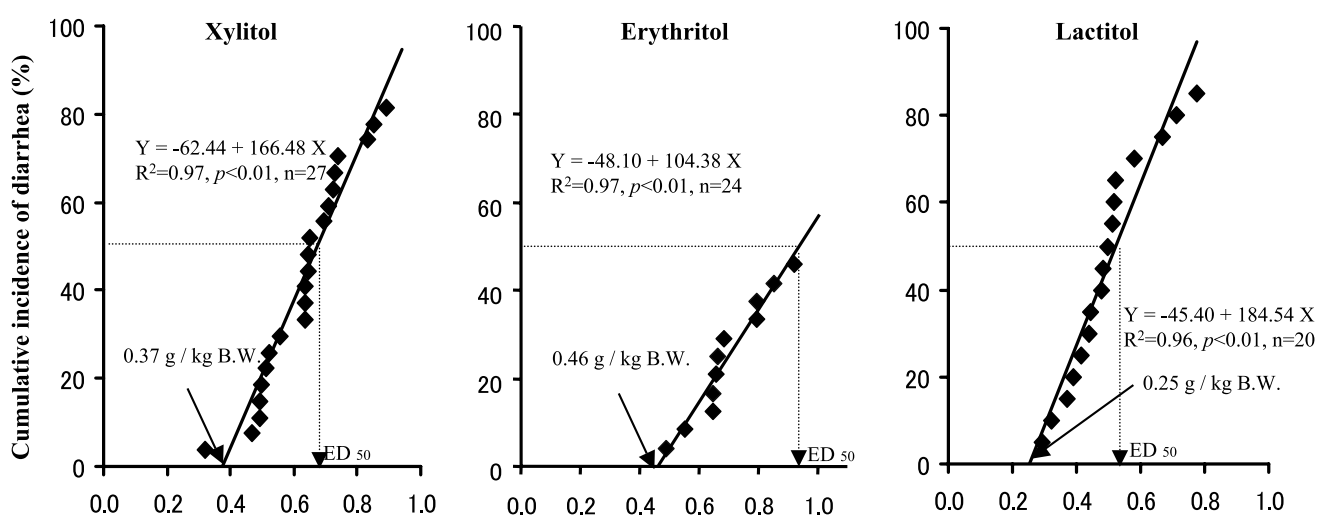

Substrate ingestion ( $\mathrm{g} / \mathrm{kg}$ Body Weight)

Fig. 1. Relationship between the amounts of xylitol, erythritol, and lactitol intake and cumulative incidence of diarrhea in normal male subjects. The minimal dosage that caused transitory diarrhea and cumulative percentage of diarrhea were calculated. $\mathrm{ED}_{50}$ is the point at which half of the subjects suffered diarrhea.

Table 4. Summary of maximal non-effective dosage and $\mathrm{ED}_{50}$.

\begin{tabular}{ccc}
\hline & $\begin{array}{c}\text { Maximal non-effective dosage } \\
(\mathrm{g} / \mathrm{kg} \text { body weight })\end{array}$ & $\begin{array}{c}\mathrm{ED}_{50} \\
(\mathrm{~g} / \mathrm{kg} \text { body weight })\end{array}$ \\
\hline Xylitol & & \\
Male & 0.38 & 0.68 \\
Female & 0.42 & 0.95 \\
Erythritol & & \\
Male & 0.46 & 0.94 \\
Female & 0.68 & 1.57 \\
Lactitol & & 0.52 \\
Male & 0.25 & 0.67 \\
Female & 0.34 & \\
\hline
\end{tabular}

subjects in order. In this study, $81.5 \%$ of subjects $(22 /$ $27=81.5 \%)$ had diarrhea after ingesting up to $50 \mathrm{~g}$ (the highest intake level) of xylitol, and the remaining subjects $(5 / 27=18.5 \%)$ were plotted. Therefore, the linear regression between test substance intake and diarrhea incidence was calculated.

The linear regression between xylitol intake and diarrhea incidence was expressed in an equation as follows:

$$
y=-62.44+166.48 x \quad\left(R^{2}=0.97, p<0.01, n=27\right)
$$

The point at which this straight line crosses the $x$ axis, namely, the y coordinate of $0 \%$ of diarrhea incidence $(y=0)$, indicates the non-effective dose level of xylitol. From Eq. (1), the non-effective dose level of xylitol was calculated as $0.38 \mathrm{~g}$ per $\mathrm{kg}$ of body weight. The dose level $\left(\mathrm{ED}_{50}\right)$ at which $50 \%$ of subjects $(n=27)$ do not have diarrhea was $0.68 \mathrm{~g}$ per $\mathrm{kg}$ of body weight (Table 4).

As shown in Fig. 1, the linear regression between erythritol intake and diarrhea incidence was given in an equation as follows:

$$
y=-48.10+104.38 x \quad\left(R^{2}=0.97, p<0.01, n=24\right)
$$

From Eq. (2), the non-effective dose level of erythritol was estimated as $0.46 \mathrm{~g}$ per $\mathrm{kg}$ of body weight. The $\mathrm{ED}_{50}$ for erythritol $(n=24)$ was $0.94 \mathrm{~g}$ per $\mathrm{kg}$ of body weight (Table 4).

Again, as shown in Fig. 1, the linear regression between lactitol intake and diarrhea incidence was given in an equation as follows:

$$
y=-45.40+184.54 x \quad\left(R^{2}=0.96, p<0.01, n=20\right)
$$

From Eq. (3), the non-effective dose level of lactitol was estimated as $0.25 \mathrm{~g}$ per $\mathrm{kg}$ of body weight. The $\mathrm{ED}_{50}$ for lactitol $(n=20)$ was $0.52 \mathrm{~g}$ per $\mathrm{kg}$ of body weight (Table $4)$.

Non-effective dose levels of xylitol, lactitol, and erythritol for transitory diarrhea in female subjects

As it was for the male subjects, the minimal amount intake ( $\mathrm{g}$ per kg of body weight) of ingestion of the test substance that caused diarrhea in Table 3 was calculated for the individual female subjects (Fig. 2). The linear regression between xylitol intake and diarrhea incidence in the female subjects was expressed in an equation as follows:

$$
y=-40.08+94.74 x \quad\left(R^{2}=0.97, p<0.01, n=28\right)
$$

From Eq. (4), the non-effective dose level of xylitol for female subjects was estimated as $0.42 \mathrm{~g}$ per $\mathrm{kg}$ of body weight. The dose level $\left(\mathrm{ED}_{50}\right)$ at which $50 \%$ of subjects did not have diarrhea was $0.95 \mathrm{~g}$ per $\mathrm{kg}$ of body weight.

As shown in Fig. 2, the linear regression between erythritol intake and diarrhea incidence was given in an equation as follows:

$$
y=-38.65+56.61 x \quad\left(R^{2}=0.95, p<0.01, n=26\right)
$$

From Eq. (5), the non-effective dose level of erythritol was estimated as $0.68 \mathrm{~g}$ per $\mathrm{kg}$ of body weight. The $\mathrm{ED}_{50}$ for erythritol $(n=26)$ was $1.57 \mathrm{~g}$ per $\mathrm{kg}$ of body weight (Table 4).

Again, as shown in Fig. 2, the linear regression between lactitol intake and diarrhea incidence was 

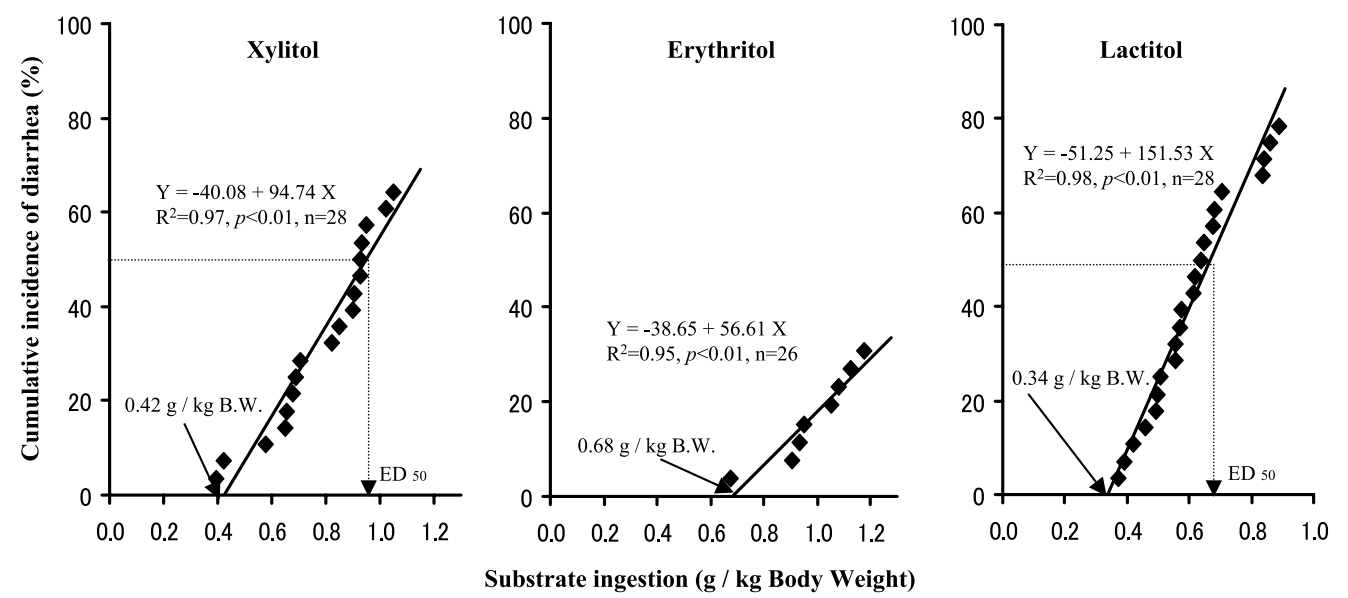

Fig. 2. Relationship between the amounts of xylitol, erythritol, and lactitol intake and cumulative incidence of diarrhea in normal female subjects. The minimal dosage that caused transitory diarrhea and cumulative percentage of diarrhea were calculated. $\mathrm{ED}_{50}$ is the point at which half of the subjects suffered diarrhea.
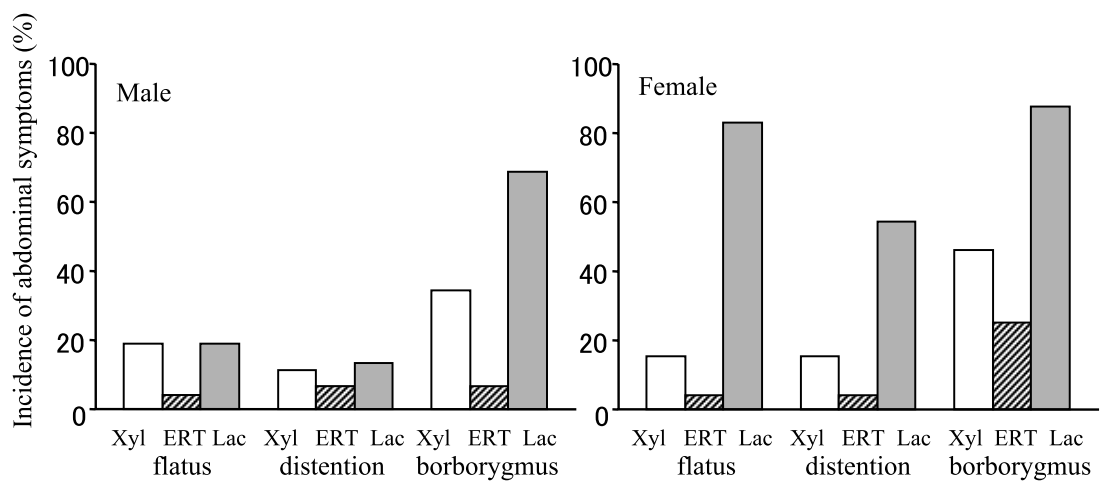

Fig. 3. Incidence of abdominal symptoms observed for the same dose level in normal male and female subjects. Xyl, xylitol; ERT, erythritol; Lac, lactitol, Dose level were $30 \mathrm{~g}$, respectively.

given in an equation as follows:

$$
y=-51.25+151.53 x \quad\left(R^{2}=0.98, p<0.01, n=28\right)
$$

From Eq. (6), the non-effective dose level of lactitol was estimated as $0.34 \mathrm{~g}$ per $\mathrm{kg}$ of body weight. The $\mathrm{ED}_{50}$ for lactitol ( $n=28$ ) was $0.67 \mathrm{~g}$ per $\mathrm{kg}$ of body weight (Table 4).

The non-effective dosages and $\mathrm{ED}_{50}$ of xylitol, lactitol, and erythritol are summarized in Table 4.

Incidence of gastrointestinal symptoms from the ingestion of test substances

The incidence of abdominal symptoms in the ingestion of each $30 \mathrm{~g}$ test substance is shown in Fig. 3. Upper and lower abdominal pain, vomiting, nausea, and thrust were experienced in very few subjects, and they were not severe. Flatus, distention, and borborymus were observed in all of the cases of the ingestion of each $30 \mathrm{~g}$ test substance.

The incidence of flatus, distention, and borborymus from the ingestion of erythritol was low in both male and female subjects. The reason is that erythritol is spontaneously absorbed from the small intestine and the amount which reaches to the lower intestine is small. These three symptoms of lactitol were frequently observed in the female rather than in male subjects.
However, a few subjects reported thirst after ingesting $30 \mathrm{~g}$ of lactitol or xylitol, and some subjects experienced thirst after ingesting larger doses ( $40 \mathrm{~g}$ and $50 \mathrm{~g}$ ) of erythritol. When the same amounts of test substances are ingested by male and female subjects, the dose level per $\mathrm{kg}$ of body weight is lower in male than female as the average body weight of males is heaver by about $15 \mathrm{~kg}$ than that of female subjects.

These results demonstrate that lactitol, which is scarcely digested by intestinal enzymes, is heavily fermented, and produces copious gas in the colon. Xylitol, which is barely absorbed from the small intestine, produces moderate amounts of gas by fermentation, and erythritol, which is readily absorbed from the small intestine, produces the smallest amount of gas. It is thought that the capacity for gas production causes abdominal symptoms.

\section{DISCUSSION}

A sufficiently high ingestion of non-digestible and/or non-absorbable sugar alcohols and oligosaccharides causes overt diarrhea, and minor symptoms such as abdominal distention, borborygmus, and flatus often arise in humans and animals (3-5). However, the diarrhea disappears in rats and human within a few days, because intestinal bacteria, which readily decompose 
these saccharides, increase during repeated ingestion $(7,23)$. Tolerance of the ingestion of these sugar substitutes, expressed as the relation between dose levels and symptoms, shows considerable individual variation. In order to estimate the non-effective dose level of xylitol, lactitol, and erythritol, the minimal amount of intake of these sugar alcohols that causes transitory diarrhea was calculated for the individual subjects. These values were used to calculate the cumulative incidence of diarrhea.

In the present study, the non-effective dose level of xylitol was $0.38 \mathrm{~g}$ per $\mathrm{kg}$ of body weight for males and $0.42 \mathrm{~g}$ per $\mathrm{kg}$ of body weight for females. That of lactitol was $0.25 \mathrm{~g}$ per $\mathrm{kg}$ of body weight for males and $0.34 \mathrm{~g}$ per $\mathrm{kg}$ of body weight for females, and that of erythritol was $0.46 \mathrm{~g}$ per $\mathrm{kg}$ of body weight for males and $0.68 \mathrm{~g}$ per $\mathrm{kg}$ of body weight for females. The non-effective dose level of xylitol was greater than that of lactitol, and was smaller than that of erythritol. These results seem reasonable, because xylitol is poorly absorbed from the small intestine, and the absorption rate is less than that of erythritol, while lactitol is not hydrolyzed.

When the same amounts, for example up to $30 \mathrm{~g}$ of xylitol were ingested by female subjects, 6 of 28 subjects experienced diarrhea, but none experienced diarrhea at the same $30 \mathrm{~g}$ level of erythritol. Thus, none experienced diarrhea at lower doses of erythritol than that of xylitol. The same subjects experienced diarrhea after ingestion of higher doses of erythritol than of xylitol. In addition, a total of $46 \%$ of all subjects reported diarrhea till ingesting $50 \mathrm{~g}$ of erythritol, while $81.5 \%$ of subjects experienced diarrhea till ingesting $50 \mathrm{~g}$ of xylitol. These results demonstrate that xylitol causes diarrhea more readily than erythritol, because the absorption rate of xylitol is less than that of erythritol.

When the gram quantities of ingested sugar substitutes are identical, low molecular weight saccharides induce higher osmotic pressure than saccharides with high molecular weight. Therefore, the non-effective dose level of oligosaccharides is commonly greater than that of monosaccharides. However, the non-effective dose level of xylitol was larger than that of lactitol, in spite of its molecular size being smaller than that of lactitol in the present study. The reason is that xylitol is partially absorbed from the small intestine. In fact, when the same amounts of xylitol and lactitol are administered to human subjects, the breath hydrogen excretion of xylitol is clearly less than that of lactitol (15).

However, this rule cannot be applied to other characteristics of sugar substitutes such as oligosaccharides and sugar alcohols. Furthermore, the non-effective dose level for transitory diarrhea depends on the body's condition and intestinal microflora. In conclusion, based on some of our previous experiments on non-effective dosages $(5,9,10,18,22)$, the acceptable value of bulking sugar substitutes that are not hydrolyzed by digestive enzymes is approximately $0.3-0.4 \mathrm{~g}$ per $\mathrm{kg}$ of body weight in healthy Japanese subjects. That is, the permissive dosage for a person of $50 \mathrm{~kg}$ of body weight is calculated to be $15 \mathrm{~g}$ per ingestion after a meal. This value means that no person is likely to experience diarrhea after ingesting up to $15 \mathrm{~g}$ of non-digestible and/or nonabsorbable sugar substitutes.

The non-effective dosage of lactitol was $0.25 \mathrm{~g}$ per $\mathrm{kg}$ of body weight for males in the present experiment. This value is slightly smaller than approximately $0.3 \mathrm{~g}$ per $\mathrm{kg}$ of body weight, the non-effective dose level of maltitol and fructo-oligosaccharide. However, the value of $0.34 \mathrm{~g}$ per $\mathrm{kg}$ of body weight for females is close to that of non-digestible sugar substitutes. Therefore, the values obtained from the present experiment seem to be reasonable.

It has been demonstrated that the non-effective dose level of erythritol, of which more than $90 \%$ ingested is absorbed from the small intestine, is $0.6 \mathrm{~g}$ per $\mathrm{kg}$ of body weight for males and $0.8 \mathrm{~g}$ per $\mathrm{kg}$ of body weight for females (9). However, the values obtained from the present study were $0.46 \mathrm{~g}$ per $\mathrm{kg}$ of body weight for males and $0.68 \mathrm{~g}$ per $\mathrm{kg}$ of body weight for females, and they were smaller than those we reported previously. In the previous study, erythritol, which was added to jelly containing agar, was ingested. But in the present study, erythritol was dissolved in about $150 \mathrm{~mL}$ of tap water before being administered. This difference in preparation may explain the contradictory results. Other possible factors include the experimental place, season, and subjects, which all differed between the present and previous experiments. The male subject's ages were very different, being older in the previous experiment and younger in the present experiment.

A small percentage of ingested xylitol is directly absorbed from the small intestine without hydrolysis $(13,14)$ but this is limited by the absorption rate in the small intestine. Therefore, when a large amount of xylitol is ingested at once, the amount transferred to the large intestine should increase. The non-effective dose level of xylitol was $0.67 \mathrm{~g}$ per $\mathrm{kg}$ of body weight for females in the previous study (1), and was $0.42 \mathrm{~g}$ per $\mathrm{kg}$ of body weight in the present study. As described above, the non-effective dose level for transitory diarrhea is affected by the absorption rate and the capacity for fermentation by intestinal bacteria. In the present study, the subjects were not specifically selected, and the age ranges and sex ratios were similar in both studies. The great difference is that the number of subjects in the present study is three times (28 subjects) that of the previous study (10 subjects). When the number of subjects is only a few, the calculated non-effective dose level is markedly affected by any subjects who are outliers. The value for the non-effective dose level of xylitol obtained from the present study appears to be true.

The non-effective dose level of xylitol was $0.38 \mathrm{~g}$ per $\mathrm{kg}$ of body weight for male and $0.42 \mathrm{~g}$ per $\mathrm{kg}$ of body weight for female subjects. The value for females was clearly larger than that for males in the present study. The non-effective dose level of lactitol and erythritol were also larger for females than for males. The noneffective dose level of maltitol and sorbitol were larger for females than for males in the other studies $(1,5)$. Although the reason why the female subjects are more 
resistant to suffering transitory diarrhea than the male subjects is not clear, the female subjects might have special microflora which an spontaneously ferment sugar alcohols.

The non-effective dose level per kg of body weight in a single ingestion depends on the digestibility and absorbability of sugar substitutes such as sugar alcohols and oligosaccharides (5). It is also influenced by other factors such ingestion at multiple times in a day (24), the properties of the test substance, and acclimation to the test substance after repeated ingestion (7). For example, the maximal permissible dose increased about 1.5 times after one container of chocolate containing lactitol was repeatedly ingested every day by healthy female subjects for $10 \mathrm{~d}$ (unpublished data).

The reason that the adaptation phenomenon occurs in humans is believed to be the repeated consumption of commercial processed food containing sugar alcohols such as xylitol, maltitol, and erythritol. Therefore, the resistance to an outbreak of transitory diarrhea will gradually increase depending on the degree of adaptation, and the non-effective dose level for the diarrhea might be increase in the future.

In conclusion, non-digestible and/or non-absorbable sugar alcohols and oligosaccharides with beneficial health effects inevitably cause overt diarrhea. Therefore, the estimation of the non-effective dose level of these sugar substitutes is essential and important to produce processed foods that the consumer can use safely and with confidence.

\section{Acknowledgments}

We wish to thank Lotte Co., Ltd. and Danisco Japan Ltd. for their financial support for this research project and for graciously providing xylitol and lactitol. We also wish to thank Nikken Chemical Co., Ltd. for their kind gift of erythritol.

This study was supported by a Grant-in-Aid for Scientific Research (B) 16390184 and Lotte Co., Ltd. and Danisco Japan Ltd.

\section{REFERENCES}

1) Oku T. 1996. Oligosaccharide with beneficial health effects: A Japanese perspective. Nutr Rev 56: S59-S66.

2) Wolfgang S, Hardi L, Thomas M. 2001. Beneficial health effects of low-digestible carbohydrate consumption. Br J Nutr 85: s23-s30.

3) Oku T, Akiba M, Myung HL, Soo JM, Hosoya N. 1991. Metabolic fate of ingested $\left[{ }^{14} \mathrm{C}\right]$-maltitol in man. J Nutr Sci Vitaminol 37: 529-544.

4) Tokunaga T, Oku T, Hosoya N. 1989. Utilization and excretion of a new sweetener, fructooligosaccharide (Neosugar), in rats. J Nutr 1 19: 553-559.

5) Oku T, Nakamura S. 2002. Digestion, absorption and fermentation of newly developed sugar substitutes and their available energy. Pure Appl Chem 74: 1253-1261.

6) Koizumi N, Fujii M, Ninomiya R, Inoue Y, Kagawa T, Sakamoto T. 1983. Study on transitory laxative effect of sorbitol and maltitol. Chemosphere 12: 45-53.

7) Tokunaga T, Oku T, Hosoya N. 1986. Influence of chronic intake of new sweetner fructooligosaccharide
(Neosugar) on growth and gastrointestinal function of the rat. J Nutr Sci Vitaminol 32: 111-121.

8) Patil DH, Grimble GK, Silk DBA. 1987. Lactitol, a new hydrogenated lactose derivative: intestinal absorption and laxative threshold in normal human subjects. $\mathrm{Br} \mathrm{J}$ Nutr 57: 195-199.

9) Oku T, Okazaki M. 1996. Laxative threshold of sugar alcohol erythritol in human subjects. Nutr Res 16: 577-589.

10) Oku T, Okazaki M. 1998. Transitory laxative threshold of trehalose and lactulose in healthy subjects. J Nutr Sci Vitaminol 44: 787-798.

11) Walker-Smith JA. 1997. Lactose intolerance. Diarrheal Disease 38: 171-187.

12) Hertzler SR, Savaiano DA, Levitt MD. 1997. Fecal hydrogen production and consumption measurements: Response to daily lactose ingestion by lactose maldigesters. Dig Dis Sci 42: 348-353.

13) Reaugerie L, Flourie B, Marteau P, Franchisseur C, Rambaud JC. 1990. Digestion and absorption in human intestine of three sugar alcohols. Gastroenterology 99: $717-723$.

14) Natah SS, Hussien KR, Tuominen JA, Koivisto VA. 1997. Metabolic response to lactitol and xylitol in healthy men. Am J Clin Nutr 65: 947-950.

15) Oku T. 1997. Comparison of digestibility and its mechanism of several oligosaccharides and sugar alcohols. In: Proceeding of IUFoST '96 Resional Sympsium on Nonnutritive Health Factors for Future Foods, p 518-521.

16) Cummings JH, Macfarlane GT. 1991. The control and consequences of bacterial fermentation in the human colon. J Appl Bacteriol 70: 443-459.

17) Wursch P, Koellreutter B, Schweizer TF. 1989. Hydrogen excretion after ingestion of five different sugar alcohols and lactulose. Eur J Clin Nutr 43: 819-825.

18) Oku T. 1996. Metabolism of sugar alcohols. Recent Res Develop Nutr Res 1: 1-13.

19) Oku T, Nakamura S. 2003. Comparison of digestibility and breath hydrogen gas excretion of fructo-oligosaccharide, galactosyl-sucrose, and isomalto-oligosaccharide in healthy human subjects. Eur J Clin Nutr 57: 1150-1156.

20) Noda K, Oku T. 1992. Metabolism and disposition of a new sweetener erythritol after oral administration to rats. J Nutr 122: 1266-1272.

21) Noda K, Nakayama K, Oku T. 1994. Serum insulin level and erythritol balance after oral administration of erythritol in healthy subjects. Eur J Clin Nutr 48: 286292.

22) Nakamura S, Oku T. 2002. Replicability of the effect of galactosylsucrose-containing food for specified health uses on fecal improvement in the case of availableness on usual life. J Jpn Dietary Fiber Res 6: 73-80 (in Japanese).

23) Oku T, Noda K. 1990. Influence of chronic ingestion of newly developed sweetener, erythritol, on growth and gastrointestinal function of the rats. Nutr Res 10: 989996.

24) Oku T, Okazaki M. 1999. Effect of single and divided ingestion of the nondigestible oligosaccharide "galactosyl-sucrose" on transitory diarrhea and laxative threshold in normal female subjects. J Jap Soc Nutr Food Sci 52 : 201-208 (in Japanese). 